\title{
Trends And Volatility In Sub Saharan Africa's Key Primary Commodity Exports
}

\author{
Matthew Kofi Ocran and Nicholas Biekpe \\ Graduate School of Business, University of Stellenbosch
}

\begin{abstract}
Using a GARCH model the paper sought to test the hypothesis that price volatility of key Sub Saharan Africa primary commodity exports, have not changed over the past four decades. Whilst crude oil, aluminium, cocoa and six others have not experienced significant change in price volatility over the period, nine other major commodities recorded changes. Efforts need to be made to extensively diversify the portfolio of agricultural commodity exports by including new products of which price volatilities in the past decades have been reduced. This is crucial for countries that depend on up to three primary commodities for the bulk of their foreign exchange earnings. Other measures such as value addition can also help in reducing impacts of unfavourable price movements.
\end{abstract}

Abstract

JEL C22, E32, 011, 55, Q17

\section{1 Introduction}

Much empirical work has generated stylised facts that indicate that volatility, trends and cyclical behaviour are inherent salient features of primary commodity prices. Recent trends in primary commodity prices have in general been unfavourable for most exporters. For instance over the last forty years real commodity prices have been continuously declining. Many reasons have been given for the long-term decline in prices. One of the important reasons for the long-term decline in trends, has been structural change particularly in agricultural commodity markets. The argument is that basic supply and demand dynamics due to increased productivity have increased supply, hence the fall in prices (FAO, 2004). However, the extent to which these features vary across individual commodities traded by various Sub Saharan African (SSA) countries has received scant attention if any at all. The fact that more than 50 per cent of SSA countries depend on up to three primary commodity exports for the greater share of their incomes (UNCTAD, 2003) makes commodity issues a subject of great concern. Therefore the role of commodities markets in the attainment of the United Nations' Millennium Development Goals (MDGs) and sustainable debt burdens for countries that have reached the completion points of the Heavily Indebted Poor Country initiative (HIPC) cannot be over-emphasised. For example lack of understanding of commodity price behaviour can erode most of the gains from debt relief obtained by commodity dependent countries. The high commodity dependence also makes exports a major source of economic destabilisation. Consequently the behaviour of commodity prices assumes increased importance in implementing meaningful economic policies and developing hedging strategies.

In the light of the above, additional information on the pattern of trends and volatility features of the individual primary commodities that are exported by SSA countries can be helpful. Despite the importance of an understanding of price behaviour of commodities of importance to SSA, the issue has not attracted adequate attention in literature.

The research questions that come to the fore are as follows, has there been change in the long-run price trend over the past forty years? 
Has the level of volatility in price changed over the study period?

The purpose of the present paper is therefore to study broadly the price behaviour of SSA's eighteen key primary commodity exports over the period 1960 to 2005. However, the specific objectives are to ascertain whether the long-run price trends and volatility have changed over the past four decades. In order to address the issues raised above, selected primary commodity prices are compared over two sub-periods to see if there have been changes. The sub-periods are the period encompassing the two major oil price shocks, i.e. 1960-1980 and the post-shock period, 1981-2005. The selection of the two sub-periods was also informed by the distinct "breakpoint" observed in the long-term trends of commodity prices as observed by FAO (2004). The FAO study asserts that the distinct "breakpoint" observed in most commodity price trends may be due to trade liberalisation, technological change and increased manufactured exports by developing countries in Asia.

The paper draws its relevance from the fact that increased insights into SSA's commodity price behaviour can be useful in the implementation of macroeconomic policy, particularly in the design of relevant policy instruments to neutralise the effects of unfavourable price movements. The paper is organised as follows; section 2 reviews briefly a selected number of studies on trends, cycles and volatility while section 3 discusses some selected stylised facts about SSA's major commodity exports. In section 4 the theoretical framework for the paper, a description of the variables used and the sources of data are presented. The empirical model and the results of the study are the subject of section 5. Section 6 discusses the conclusions and the policy implications of the study.

\section{2}

\section{Literature review}

This section of the paper briefly reviews literature relating to the study. Papers that have considered commodity price cycles, volatility and trends are therefore discussed. The discussion identifies a gap with respect to key primary commodity exports of major importance to SSA economies. An attempt is made to fill this gap by focusing on the eighteen key primary commodity exports that most SSA countries depend on for the bulk of their foreign exchange earnings.

Agenor et al. (2000), Reinhart and Wicham (1994) and Cashin, Liang and McDermot (2000) have shown that commodity price shocks that trigger commodity price cycles can display varying degrees of persistence across commodities. However, two approaches emerge in the literature on the duration of commodity price cycles. The Beveridge-Nelson decomposition defines cycles in terms of deviation of a price series from a trend-growth cycle (Cuddington, 1994; Reinhart \& Wicham, 1994). The second approach which is often used in literature (Watson, 1994; Cashin \& McDermott, 2002) deals with the price data in levels. The approach thus avoids the element of subjectivity inherent in the selection of detrending methods. Consequently, price slumps and booms are then expressed as periods of absolute decreases and increases respectively in the price series and not as periods below trend or above trend. The classical definition therefore renders the decomposition of a series into its "trend" and "cycle" components redundant. Following the seminal work of Burns and Micthel (1946) in the study of business cycles, the definition of booms and slumps depends on movement of prices between peaks and troughs. Commodity prices are therefore said to have moved from a boom to slump phase if prices fall from their earlier (local) peak.

Most previous studies on commodity price volatility (uncertainty) have examined the phenomenon with either unconditional standard deviation or the coefficient of variation (see UNCTAD, 2003; Marinkov \& Burger, 2005). Volatility measures based on time series in which cyclical components are filtered out like that provided by the Holdrick-Prescott and the Bandwith filters, have been criticised as ineffective (see Agenor et al., 2000; Canova, 1998; Harding \& Pagan, 2002). It has indeed been argued quite strongly that the exercise leads to loss of certain features in the time series that rob researchers of full information regarding a given series. 
Clem (1985) found that the volatility indices for food commodities were consistently higher than those of non-food. The paper used two alternate measures of volatility: A static $\mathrm{x}$ and dynamic volatility measure. These measures were based on two different definitions of volatility. Whilst the former depended on changes in price level, the latter considered changes in the rate of change.

Generally the literature points out that volatility measures like standard deviation and coefficient of variation are reckoned to overstate variability in non-trending series. They are also deemed to have no constant range; their squaring further tends to aggravate the problem of outliers (Offut \& Blandaford, 1986). The possibility of variation over time in the confidence interval of volatility forecasts calls for an approach that models the variance of the errors. The body of knowledge on volatility identifies the ARCH-type of models as the most suitable in the assessment of volatility (Bollerslev, 1986, Zukonian, 1994; Swarmy, 2002).

Previous studies that considered trends in commodity prices present two main approaches. One group of researchers asserts that difference stationary ought to be used in describing the underlying data-generating processes of commodity prices. Grilli and Yang (1988) used the time trend approach; however, in a study by Cuddington and Uzua (1998) it was found that the use of either difference stationary or trend stationary did not make any difference in the results.

\section{3}

\section{SSA'S major commodity exports: selected stylised facts}

SSA countries export over 60 assorted primary commodities, but 19 of these happen to be among the three leading exports of countries in the region. These primary commodities can be broadly classified into (i) agricultural raw materials, (ii) minerals including crude oil, and (iii) food and beverages. As indicated earlier in the paper, the typical SSA country depends on three or less of these primary commodities for more than 50 per cent of their foreign exchange earnings. The region's commodity problem is defined in terms of the continued heavy dependence on primary commodity exports (Ocran \& Biekpe, 2005).

In order to get some understanding of the volatility of the real prices of the commodities being studied, we calculated the percentage month-on-month changes in real prices and plotted them against time (Figure 1). A cursory look at the charts indicates that all the major commodities have seen tremendous volatility in prices, with the worst being crude oil; This commodity recorded the highest peaks during the oil price shocks in 1973 and 1978. The first shock was a result of the Yom Kippur war that caused major Arab oil-producing countries to cut back on production. These oil producers also placed an embargo on oil exports to perceived pro-Israel countries such as the US and the Netherlands. The second oil shock could be described as the Iranian oil price shock. Following the deposition of the Shah of Iran and the assumption of power by the Ayatollah Khomeini, border clashes between Iran and Iraq developed into full-scale war, which led to the shutting down of Iranian oil production facilities. At the time Iran accounted for about 20 per cent of the world's supply of crude oil, and hence the gap left by the absence of Iranian output led to a severe price shock. The invasion of Afghanistan by the Soviet Union around the same time did not help matters as this led to panic buying in anticipation of a major world crisis.

Groundnuts was another commodity that saw huge price changes, with tobacco as the commodity that recorded very modest price changes, that did not exceed 5 per cent in any month-on-month period over the years 19652005. As the developed world becomes more affluent there is an increased demand for sea foods that probably accounts for the big positive spikes in the prices of shrimps (figures below). 


\section{Figure 1}

Month-on-month changes in real prices 1960(1) - 2004(12)
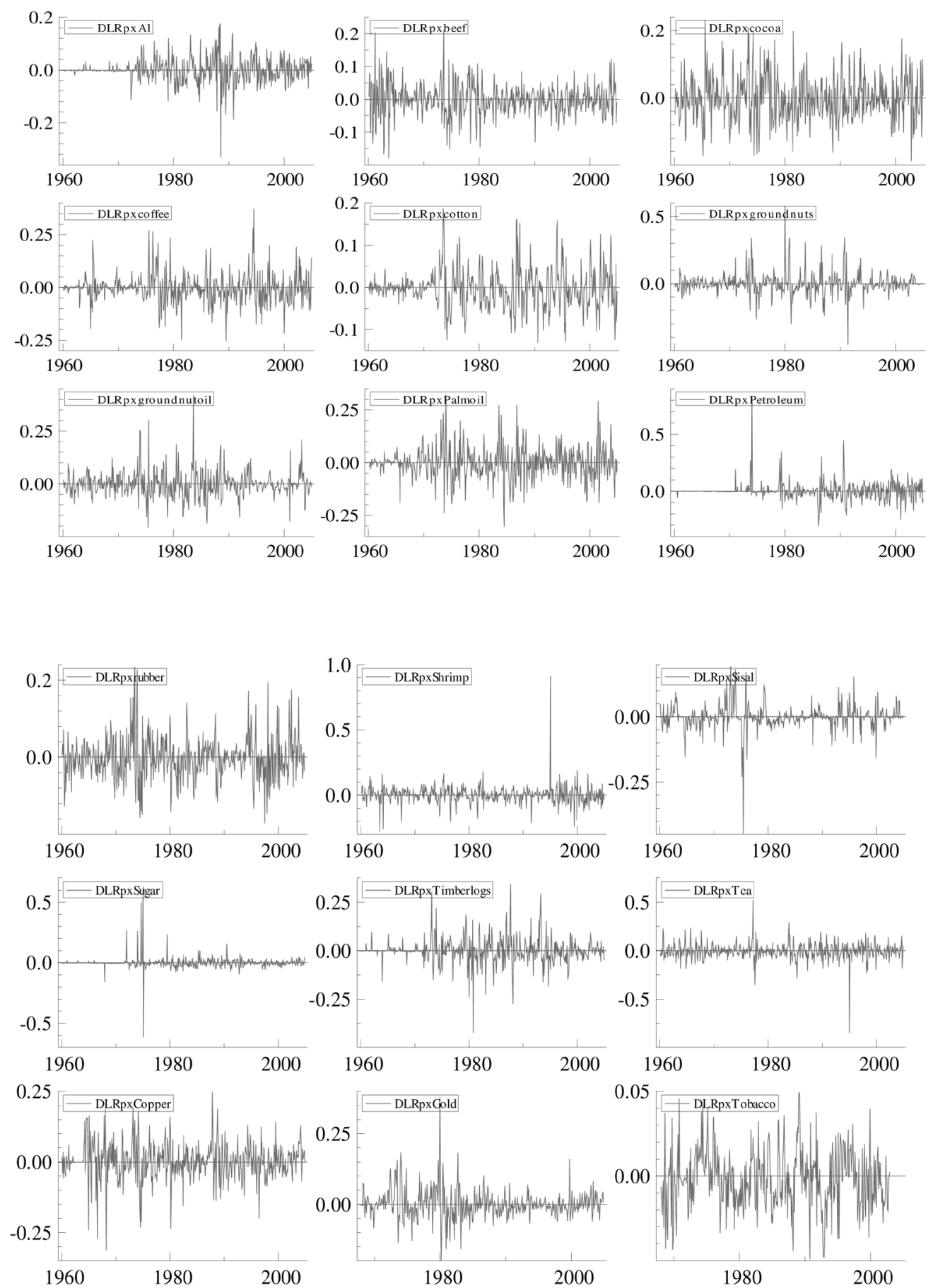


\section{Appendix}

\section{Figure 1}

Month-on-month changes in real prices 1960(1) - 2004(12)
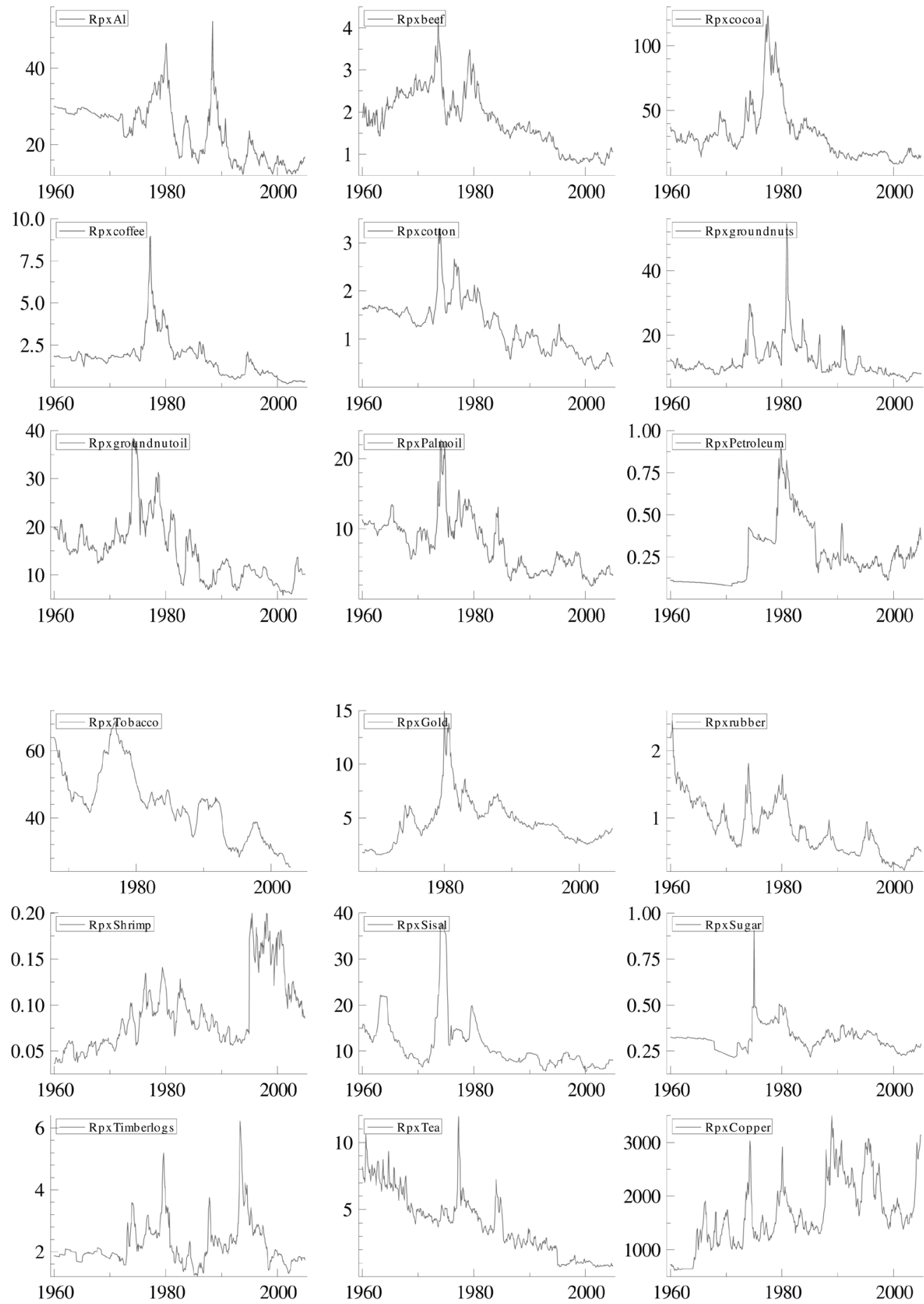
4

Methodology

The analytical framework for validating the set of hypotheses for the preceding section has two dimensions. First, we respectively present the ADF and Phillips-Peron frameworks testing for unit roots. The second part of this section presents the theoretical underpinnings for the volatility assessment and the adopted GARCH model is briefly discussed. The GARCH approach was chosen out of the range of volatility models because of its best fit statistically, particularly in modelling commodity prices (Swaray, 2002).

\subsection{Trends in Sub-Saharan Africa's key commodity exports}

Studies have indicated that before one proceeds to measure the temporal variation in the second moments of a time series, it is important that other specifications of its trend are considered (Cuddington \& Liang, 1998). However, there appears to be some debate among researchers about whether difference stationary (DS) or trend stationary (TS) models are more appropriate in describing the data-generating processes. Following Cuddington and Liang (1998), we first examine the statistical properties of the price series by testing for unit roots using both the Augmented Dickey-Fuller Test and the Phillips-Peron Test.

Understanding the underlying cause of nonstationarity helps in addressing the question of whether price shocks have permanent consequences for future levels of commodity prices or whether they rather represent temporary setbacks that have no permanent consequences (Hamilton, 1994).

$\log p_{t}=\alpha+\beta T+e_{t}$ $(1-\rho) A(L) e_{t}=\beta(L) \varepsilon_{\mathrm{t}}$

where $p_{t}$ is the natural log of real commodity price index and $T$ is the trend variable Time. The error process in (2) is written with the largest root factorised out. It is also assumed that the lag polynomial $A(L)$ is invertible and likewise $B(L)$; therefore $A(L)^{-1}(B) L$ is a stable polynomial lag operator. It is serially uncorrelated with zero mean and finite variance. If $\rho=1$ in equation (2), the data process underlying the commodity process is said to have a unit root. In that case we first difference equation (1). The presence or otherwise of a unit root is tested with a PhillipsPerron test; this examines the significance of the regression below:

$d \log p_{t}=\mu+\theta \log p_{t-1}+\beta T+\mu_{\mathrm{t}}$

where $\theta=\rho-1$ and $d \log p_{t}$, the first difference of $\log$ of $p$. The ordinary least squares regression estimate of the above model and the t-test for the null hypothesis $\theta=0$ or $(\rho-1)$ are then obtained. First equation (3) is estimated at the least restrictive level with the inclusion of a constant and time, $\mathrm{T}$. If the null hypothesis is not rejected, the significance of the constant and trend terms are explored to ascertain whether the model will gain more power dropping one or both terms (Enders, 1995).

It can be asserted that 7 out of the 18 major primary commodity prices in SSA underwent changes that appear to have had a permanent effect on the real prices of the commodities concerned (see Table 1 on the next page).

Table 2 (on the next page) presents the results of the Phillips-Peron tests on SSA major primary commodities examined in the present study. Data for the tests were drawn from the International Monetary Fund (IMF) International Financial Statistics (IFS) CD ROM and they spanned the period 1960(1) to 2004(12). The third column of the table presents the kind of model selected for the analysis; I denotes model with intercept and $T$ model with trend. For all the series except groundnuts, the null hypothesis of $\theta=0$ was rejected at the 5 per cent level. 
Table 1

Unit root test results for real prices of SSA's key commodity exports

\begin{tabular}{|l|c|c|c|c|}
\hline Real commodity price & Model selected & Lag order $\gamma$ & Coefficient $\beta$ & t-ADF t $(\beta)$ \\
\hline Aluminium & $\mathrm{I}, \mathrm{T}$ & 5 & 0.965 & $-3.632^{* *}$ \\
\hline Beef & $\mathrm{I}, \mathrm{T}$ & 0 & 0.975 & $-2.922^{*}$ \\
\hline Cocoa & $\mathrm{I}, \mathrm{T}$ & 9 & 0.984 & -2.546 \\
\hline Coffee & $\mathrm{I}, \mathrm{T}$ & 10 & 0.986 & -2.591 \\
\hline Copper & $\mathrm{I}, \mathrm{T}$ & 1 & 0.975 & $-3.937^{*}$ \\
\hline Cotton & $\mathrm{I}, \mathrm{T}$ & 1 & 0.978 & $-3.619^{* *}$ \\
\hline Gold & $\mathrm{I}$ & 12 & 0.986 & -2.588 \\
\hline Groundnuts & $\mathrm{I}, \mathrm{T}$ & 1 & 0.963 & $-3.780^{* *}$ \\
\hline Groundnut oil & $\mathrm{I}, \mathrm{T}$ & 6 & 0.972 & $-3.510^{*}$ \\
\hline Palm oil & $\mathrm{I}, \mathrm{T}$ & 5 & 0.962 & $-3.556^{* *}$ \\
\hline Petroleum & $\mathrm{I}, \mathrm{T}$ & 4 & 0.987 & -2.068 \\
\hline Rubber & $\mathrm{I}, \mathrm{T}$ & 12 & 0.962 & $-4.187^{* *}$ \\
\hline Shrimp & $\mathrm{I}, \mathrm{T}$ & 3 & 0.968 & $-3.062^{*}$ \\
\hline Sisal & $\mathrm{I}, \mathrm{T}$ & 11 & 0.973 & $-4.140^{* *}$ \\
\hline Sugar & $\mathrm{I}$ & 0 & 0.963 & $-3.114^{*}$ \\
\hline Tea & $\mathrm{I}, \mathrm{T}$ & 11 & 0.979 & -2.785 \\
\hline Timber & $\mathrm{I}$ & 0.962 & $-3.764^{* *}$ \\
\hline Tobacco & & -3.173 \\
\hline
\end{tabular}

Note: Critical values used in the ADF test were; 5 per cent $=-2.87$ and 1 per cent $=-3.45$

** denotes significance at 1 per cent and * denotes significance at 5 per cent.

Source: Data used in the analysis was obtained from the International Monetary Fund's International Financial Statistics CD ROM, August 2005. The data were monthly data from 1960(1) to 2004(12) except for gold and tobacco. The tobacco series began in 1969 and ends in 2002 whereas gold begins in 1976 and ends in 2004.

Table 2

Phillips-Peron unit root test results for real prices of SSA's key commodity exports

\begin{tabular}{|l|c|c|}
\hline Commodities & Test-Statistic & Model Selection \\
\hline Aluminum & -2.120 & $\mathrm{I}$ \\
\hline Beef & -2.736 & $\mathrm{I}$ \\
\hline Cocoa & -1.540 & $\mathrm{I}$ \\
\hline Coffee & -1.889 & $\mathrm{I}$ \\
\hline Copper & -3.302 & $\mathrm{I}$ \\
\hline Cotton & -1.159 & $\mathrm{I}$ \\
\hline Gold & -1.988 & $\mathrm{I}$ \\
\hline Groundnut & $-3.079 * *$ & $\mathrm{I}$ \\
\hline Groundnut oil & -2.253 & $\mathrm{I}$ \\
\hline Timber & -3.252 & $\mathrm{I}$ \\
\hline
\end{tabular}




\begin{tabular}{|l|c|c|}
\hline Palm oil & -3.247 & $\mathrm{I}, \mathrm{T}$ \\
\hline Petroleum & -1.666 & $\mathrm{I}$ \\
\hline Rubber & -3.209 & $\mathrm{I}, \mathrm{T}$ \\
\hline Shrimp & -2.600 & $\mathrm{I}$ \\
\hline Sisal & -2.364 & $\mathrm{I}$ \\
\hline Sugar & -2.758 & $\mathrm{I}$ \\
\hline Tea & -3.418 & $\mathrm{I}, \mathrm{T}$ \\
\hline Tobacco & -1.003 & $\mathrm{I}$ \\
\hline
\end{tabular}

Notes: $\quad * * *$ Denotes significance at 1 per cent

Source: Data used in the analysis was obtained from the International Monetary Fund's International Financial Statistics CD ROM, August 2005. The data were monthly data from 1960(1) to 2004(12) except for gold and tobacco. The tobacco series began in 1969 and ends in 2002 whereas gold begins in 1976 and ends in 2004.

\subsection{Commodity price volatility}

Following the seminal work by Engle (1982) that led to the autoregressive conditional heteroskedasticity $(\mathrm{ARCH})$ model, which makes use of a time-varying and measurable function of the time $\mathrm{t}-1$ information set, various extensions of the model have emerged over the years. One of these extensions is the generalised $\mathrm{ARCH}$ model (GARCH). See Gourieoux, (1997) and Bollerslev (1992) for an extensive discussion of the various extensions. The linear ARCH (q) models usually call for a long lag length "q". An alternative and more flexible lag structure is offered by the GARCH extension GARCH (p, q), as presented in Bollerslev (1986). It is, however, worth noting that the simple GARCH $(1,1)$ was independently suggested by Taylor (1986). In fashioning out the theoretical framework for the GARCH model used in the present work, the approach is first explained by way of a discussion of the basic ARCH model, from where extensions are made to derive the GARCH model. Given that the dependent variable of primary commodity prices is denoted $p_{t}$ and that this is a result of an autoregressive process,

$$
p_{t}=\eta_{0}+\sum_{i=1}^{k} \eta_{i} p_{t-1}+\varepsilon_{t}
$$

An $\mathrm{ARCH}$ (p) process is obtained by expressing the conditional variance of (1) as a function of its past values squared:

$$
\varepsilon_{t} \mid \Omega_{t-1} \sim N(0, \sigma)
$$

$\sigma_{t}=\delta+\sum_{i=1}^{p} \alpha_{i} \varepsilon_{t-1}^{2}$

where $\sigma^{2}$ stands for the conditional variance of the information set $\Omega_{t-1}$ available at time t-1 and $\delta_{1} \succ 0, \alpha_{i} \geq 0$ for all $i=2, \ldots . . p$ and $\alpha_{1}+\alpha_{2}+\ldots \ldots \ldots . \alpha_{n} \prec 1$ are required to render $\varepsilon_{t}^{2}$ positive and covariance stationary. Bollerslev (1986) extended the framework represented in (3) into (4), which incidentally is an autoregressive moving average (ARMA) representation of $\varepsilon_{t}^{2}$.

$\sigma_{t}^{2}=\delta+\sum_{i=1}^{p} \alpha_{i} \varepsilon_{t-1}^{2}+\sum_{i-1}^{q} \beta_{i} \sigma_{t-1}^{2}$

The resultant ARCH extension represented by (4) denotes conditional variance of a commodity price series that depends on a constant, past information about volatility (i.e., $\varepsilon_{t-1}^{2}$ terms) and past forecast variance (the $\sigma_{t-1}^{2}$ terms). Consequently the lagged conditional variances can be said to capture the adaptive learning phenomenon that characterises the process. A simpler form of equation (4), first suggested by Taylor (1986), is the GARCH $(1,1)$ model;

$\sigma_{1}^{2}=\delta+\alpha \varepsilon_{t-1}^{2}+\beta \sigma_{t-1}^{2}$

One of the strengths of the formulation in (5) is its ability to make do with fewer coefficient restrictions. Another appealing feature of the GARCH $(p, q)$ is the model's time series dependence on $\varepsilon_{t}^{2}$. However, for a well-defined 
variance and covariance function of the model, its coefficients ought to lie inside a unit circle:

$\delta, \alpha \succ 0 ; \beta \geq 0$ and $\alpha+\beta \prec 1$.

It is also important to note that the sum of $\alpha+\beta$ is a measure of volatility persistence.

\subsection{Data issues}

The US dollar prices of the commodities selected for the study were obtained from IMF's International Financial Statistics database CD-ROM, August 2005 issue. The monthly price data spanned the period January 1960 to December 2004. Real commodity prices were generated by deflating the nominal commodity prices using the US consumer price indices. The CPI indices were obtained from the IMF's IFS CD ROM. The eighteen leading commodities selected for the study were obtained from an UNCTAD study that identified the key leading exports from SSA (UNCTAD, 2003). Commodities considered in the study were: aluminium, bananas, beef, cocoa, coffee, copper, cotton, crude oil, gold, timber, groundnut oil, groundnut, hides, palm oil, rubber, shrimps, sugar, tea, tobacco. The descriptive statistics of the commodity prices are presented in Table 3 .

The price variable in commodity studies is defined differently in the literature. Heifer and Kinishita (1999) used nominal and real prices from USDA for price. However, in an earlier study Blandford (1983) simply used nominal prices, while in their paper Leon and Soto (1997) used real dollars. Cashin, McDermott and Scott (1999a and 1999b) used the IMF reference international commodity prices deflated by manufacturing unit value index. In a study by Dehn (2004), the author constructed an index of CIF prices in US dollars. Again, Cashin and McDermott (2001), unlike their earlier study, used commodity price weighted by imports and deflated by the US CPI. In the present study, however, we deflate the IMF's commodity prices in US dollars with the US CPI. We felt that since the IMF prices were recorded in US dollars, the most appropriate deflator was the GDP deflator. But these were not available in monthly series for the US economy, hence the use of the CPI.

Table 3 below presents the descriptive statistics of the eighteen key SSA commodities studied. First, the chi ${ }^{2}$ asymptotic and normality tests indicate significant deviation from normal distribution of the prices of each of the commodities. Again, results describing significant excess kurtosis and skewness in the series further reinforce the normality statistic. Generally, all the real prices were leptokurtic (i.e., exhibited fat tails) just like the prices of most financial assets. Apart from groundnuts, sisal, hardwood timber logs, cocoa and sugar, all the other commodities were significantly skewed to the right, i.e. the right tails of the various distributions were heavier to the left of the means of the commodities. Aluminium and beef recorded the least skewness in the commodity group under discussion. Whilst aluminium and beef were fairly platykurtic, the rest had very prominent spikes, with groundnuts and sisal exhibiting the highest peak. The least excess kurtosis was seen in shrimps. The stylised facts presented by the summary statistics are consistent with most of the literature (Deaton, Laorwue, 1992; Cashin, McDermott \& Scott, 1999; Swarmy, 2002).

Table 3

Desctiptive statistics of selected real commodity prices, 1960M1-2004M12

\begin{tabular}{|l|r|r|r|r|r|c|}
\hline Commodities & Mean & Min. & Max. & $\begin{array}{c}\text { Standard } \\
\text { deviation }\end{array}$ & Skewness & $\begin{array}{c}\text { Excess } \\
\text { kurtosis }\end{array}$ \\
\hline Aluminum & 23.55 & 12.83 & 52.21 & 7.27 & 0.33 & -0.31 \\
\hline Beef & 1.82 & 0.73 & 4.26 & 0.69 & 0.37 & -0.33 \\
\hline Cocoa & 31.56 & 8.65 & 123.25 & 20.92 & 1.92 & 4.00 \\
\hline Coffee & 7.66 & 1.81 & 22.66 & 3.82 & 0.80 & 0.80 \\
\hline
\end{tabular}




\begin{tabular}{|l|r|r|r|r|r|r|}
\hline Copper & 37.60 & 13.50 & 108.57 & 18.11 & 1.20 & 1.33 \\
\hline Cotton & 1.29 & 0.36 & 3.29 & 0.54 & 0.56 & 0.59 \\
\hline Gold* & 5.16 & 2.53 & 14.92 & 2.25 & 1.71 & 3.75 \\
\hline Groundnut oil & 14.80 & 5.77 & 38.39 & 6.41 & 1.16 & 1.76 \\
\hline Groundnuts & 12.14 & 5.61 & 54.50 & 5.58 & 3.02 & 14.20 \\
\hline Palm oil & 7.66 & 1.81 & 22.66 & 3.82 & 0.80 & 0.80 \\
\hline Petroleum & 0.26 & 0.08 & 0.90 & 0.40 & 1.30 & 1.44 \\
\hline Rubber & 0.84 & 0.22 & 2.45 & 0.40 & 0.88 & 0.79 \\
\hline Shrimp & 0.09 & 0.04 & 0.20 & 0.04 & 0.98 & 0.17 \\
\hline Sisal & 11.30 & 5.58 & 37.85 & 5.78 & 2.49 & 7.55 \\
\hline Sugar & 0.32 & 0.22 & 0.91 & 0.07 & 1.80 & 10.15 \\
\hline Tea & 3.91 & 0.71 & 11.92 & 2.32 & 0.43 & -0.51 \\
\hline Timber & 2.22 & 1.22 & 6.22 & 0.72 & 2.07 & 5.96 \\
\hline Tobacco & 43.82 & 25.36 & 68.86 & 10.31 & 0.35 & -0.49 \\
\hline
\end{tabular}

Notes: Data span the period 1963(1) to 2004(12).

\section{5}

\section{Results}

\subsection{Commodity price volatility}

Following Cuddington and Liang (1998) and Swaray (2002), this paper has sought to ascertain the suitability of GARCH as a good descriptor of the price instability in the 18 commodities under discussion. GARCH $(1,1)$ was therefore fitted for each of the commodities. Interestingly, the estimated coefficients of the variance equation for every one of the commodities were found very significant at the 1 per cent level of significance, except for tobacco (see Table 4). The univariate $\operatorname{GARCH}(1,1)$ estimates for the mean and variance equations of the eighteen commodities under discussion are presented in Table 4 below. Thirteen of the eighteen commodities exhibited relatively high coefficient estimates for the variance equations, whilst the parameter estimate for tobacco was low - it was statistically insignificant. On the other hand, low and significant variance equation estimates were observed for cotton, sisal, tea and cocoa. In order to validate the hypothesis that price volatility for SSA key commodity exports varied between the two periods, 1960-1980 and 19812004, we introduced a time dummy that took on the value of unity in the later period and zero in the former. Half of the commodities under discussion did not experience statistically significant volatility changes over the two periods. These commodities were aluminium, beef, cocoa, groundnut oil and palm oil.

Table 4

Estimation of the GARCH $(1,1)$ model, 1960(1) - 2004(12)

\begin{tabular}{|l|c|c|c|c|c|}
\hline Commodity & Constant & ARCH(1) $(\alpha)$ & GARCH $(\mathbf{1}(\beta)$ & Time dummy & Log-likelihood \\
\hline Aluminium & $5.05 \mathrm{E}-06^{*}$ & $0.1881^{*}$ & $0.8517^{*}$ & $-1.13 \mathrm{E}-05$ & 1109.111 \\
\hline Beef & $9.75 \mathrm{E}-05^{*}$ & $0.1457^{*}$ & $0.8112^{*}$ & $-1.43 \mathrm{E}-06$ & 933.2172 \\
\hline Cocoa & $0.0011^{*}$ & $0.3062^{*}$ & $0.5078^{*}$ & -0.000198 & 0.001053 \\
\hline Coffee & $4.78 \mathrm{E}-05^{*}$ & $0.2717^{*}$ & $0.7618^{*}$ & $0.0002^{*}$ & 776.873 \\
\hline Cotton & $7.99 \mathrm{E}-05^{*}$ & $0.5741^{*}$ & $0.3766^{*}$ & $0.0005^{*}$ & 1034.719 \\
\hline
\end{tabular}




\begin{tabular}{|l|l|l|l|l|l|}
\hline Groundnut & $0.0005^{*}$ & $0.2460^{*}$ & $0.7301^{*}$ & $-0.0001^{*}$ & 685.2739 \\
\hline Groundnut oil & $0.0003^{*}$ & $0.3878^{*}$ & $0.6149^{*}$ & $2.85 \mathrm{E}-05$ & 820.1029 \\
\hline Palm oil & $4.54 \mathrm{E}-05^{*}$ & $0.0920^{*}$ & $0.8994^{*}$ & $8.71 \mathrm{E}-05$ & 706.8984 \\
\hline Petroleum & $0.0002^{*}$ & $0.5712^{*}$ & $0.6052^{*}$ & $2.02 \mathrm{E}-05$ & 845.8932 \\
\hline Rubber & $4.54 \mathrm{E}-05^{*}$ & $0.0920^{*}$ & $0.8994^{*}$ & $8.71 \mathrm{E}-05$ & 706.8984 \\
\hline Shrimp & $2.71 \mathrm{E}-06^{*}$ & $-0.0114^{*}$ & $1.018012^{*}$ & $-3.65 \mathrm{E}-05^{*}$ & 712.3838 \\
\hline Sisal & $0.0004^{*}$ & $0.5664^{*}$ & $0.4032^{*}$ & $-0.0001^{*}$ & 1036.266 \\
\hline Sugar & 0.000219 & $0.3853^{*}$ & $0.7312^{*}$ & $-0.0002^{*}$ & 1044.996 \\
\hline Timber & $0.0002^{*}$ & $0.2391^{*}$ & $0.7518^{*}$ & $1.05 \mathrm{E}-05$ & 832.0788 \\
\hline Tea & $0.0016^{*}$ & $0.2410^{*}$ & $0.4825^{*}$ & $0.0015^{*}$ & 586.3338 \\
\hline Copper & $5.43 \mathrm{E}-05^{*}$ & $0.3347^{*}$ & $0.6899^{*}$ & $0.0002^{*}$ & 781.4507 \\
\hline Gold & $0.0002^{*}$ & $0.1630^{*}$ & $0.8026^{*}$ & $-0.0001^{* *}$ & 781.7768 \\
\hline Tobacco & $0.0002^{*}$ & $0.3084^{*}$ & 0.2113 & $-3.75 \mathrm{E}-06$ & 1119.462 \\
\hline
\end{tabular}

Notes: $\quad *$ denotes significance at 1 per cent level of significance;

** mean significant at 5 per cent level of significance.

The other commodities that did not show any meaningful change in volatility over the past four decades were crude oil, rubber, timber and tobacco. On the other hand, the other half of the range of commodities did indeed experience changes in the level of volatility over the two periods. Certain commodities recorded increased volatility in the second period (coffee, cotton, tea, copper and rubber), while others saw a relative decline in their price volatility (sugar, groundnut, gold and shrimp).

The literature indicates that the magnitude of the summation of the ARCH and GARCH terms in the variance equation is an indication of the measure of persistence in volatility shocks. When the sum of the coefficients of the $\mathrm{ARCH}$ and GARCH terms amounts to unity, the implication is that shocks dampen out quite slowly; thus the lower the value of the terms, the faster volatility shocks die out. Persistence measures that approach unity are an indication of the presence of an integrated GARCH (IGARCH) phenomenon. Consequently, it can be asserted that the autoregressive moving average (ARMA) process of the variance in a given commodity price could be either non-stationary or possess an infinite variance. The presence of an IGARCH process in most of the region's major (15) primary commodities, underscores an incessant variation in the volatility levels of their prices. Whilst tobacco, cocoa and tea had the least measure of persistence, crude oil prices exhibited the highest level of volatility persistence; this was followed by sugar, aluminium and coffee (See Table 5 below). The level of volatility persistence obtained for the beverages cocoa, coffee, tea and for tobacco compared favourably with that obtained by Swaray (2002).

Table 5

Volatility persistence in commodity prices

\begin{tabular}{|l|c|}
\hline Commodities & Volatility persistence, $(\tau=\alpha+\beta)$ \\
\hline Petroleum & 1.18 \\
\hline Sugar & 1.12 \\
\hline Aluminum & 1.04 \\
\hline Coffee & 1.03 \\
\hline Shrimp & 1.01 \\
\hline
\end{tabular}




\begin{tabular}{|l|l|}
\hline Groundnut oil & 1.00 \\
\hline Palm oil & 0.99 \\
\hline Timber & 0.99 \\
\hline Cotton & 0.98 \\
\hline Groundnuts & 0.97 \\
\hline Sisal & 0.97 \\
\hline Gold & 0.97 \\
\hline Beef & 0.96 \\
\hline Copper & 0.95 \\
\hline Rubber & 0.90 \\
\hline Cocoa & 0.81 \\
\hline Tea & 0.72 \\
\hline Tobacco & 0.52 \\
\hline
\end{tabular}

Source: Authors' computations using EViews.

\section{6}

\section{Conclusion}

Using the GARCH model the paper empirically investigated the persistence of shocks in SSA's major primary prices and again ascertained the asymmetry pattern or otherwise in the nature of the price volatilities. The differences in SSA's real commodity prices across commodities were examined. The maintained hypothesis that variability in price volatility had not changed for the prices over the past 40 years was examined. The paper also sought to ascertain whether volatility in the region's key commodity prices had increased or decreased after the 1980s as compared to the period 1960-1980, when the world suffered two major oil price shocks.

The highlights of the study can be summarised as follows. For nine of the major exports, volatility variation did not show any significant change over the past forty years. These commodities were aluminium, beef, cocoa, groundnut oil, crude oil, palm oil, rubber, timber and tobacco. On the other hand, the other nine commodities saw changes in volatility variations. However, whilst gold, sisal, shrimps, groundnuts and sugar saw a decrease, the rest rather witnessed deterioration in levels of volatility (i.e., copper, coffee, cotton, tea and sisal).

Clearly, evidence of long-run volatility persistence in the major primary commodity prices of interest to SSA can be adduced. For these commodities international stabilisation efforts such as that supported by commodity organizations like the International Coffee and Cocoa Organization (ICCO) cannot be perpetually sustained. Usually when commodity prices soar as result of the volatility phenomenon government revenues receive a boost from the windfalls either directly or indirectly, or better still both directly and indirectly. In countries where governments control commodity marketing organisations, the impact on revenues has been direct. Indirect impacts are realised in instances where commodity trade is in private hands; in this case revenue from trade taxes and income taxes surge. Governments in SSA have typically assumed that positive commodity price shocks are enduring, whilst negative shocks are rather transitory (Cooper, 1991). Indications are that the windfall gains are often used to provide funding for pro-cyclical expenditures. Consequently, when the trend for prices is downward, these countries have had to run huge fiscal deficits (see Collier \& Gunning, 1996).

It is important that governments realise that price swings are a more or less permanent feature and that when positive shocks are experienced efforts need to be made to save for a rainy day. The collapse of the various stabilisation schemes under the strain of 
continued swings in prices further underscores the inadequacy of external attempts aimed at lessening the effects of negative price shocks. It is important that governments in SSA pursue expenditure smoothening policies so that savings can be made at good times and dissaving in difficult periods. Additionally, efforts need to be made to diversify extensively their portfolio of primary agricultural commodity exports by including new products that appear to have reduced price volatilities in the past decades. This is crucial for countries that depend on three agricultural primary commodities for the bulk of their foreign exchange earnings. Other measures such as value addition can also help in reducing impacts of unfavourable price movements.

\section{References}

1 AGENOR, P.R., MCDERMOTT, C.J. \& PRASAD, E. (2000) "Macroeconomic fluctuations in developing countries: Some stylized facts", World Bank Economic review, 14: 251-286.

2 BOLLERSLEV, T. (1986) "Generalized autoregressive conditional heteroskedascity", Journal of Econometrics, 31: 307-327.

3 BURNS, A.F. \& MICTHEL, W.C. (1946) "Measuring business cycles" National Bureau of Economic Research (NBER) Studies in Business Cycles, 2.

4 CANOVA, F. (1998) "Detrending and business cycle facts", Journal of Monetary Economics, 41: 475-512.

5 CASHIN, P., LIANG, H. \& McDERMOTT, C.J. (2001) "How persistent are shocks to world commodity prices?", IMF Working Paper, 80.

6 CASHIN, P., MCDERMOTT, C.J. \& SCOTT, A. (1999a) "Booms and slumps in world commodity prices", IMF Working Paper, WP/99/155.

7 CASHIN, P., MCDERMOTT, C.J. \& SCOTT, A. (1999b) "The myth of co-moving commodity prices", Reserve Bank of New Zealand Discussion Paper, G99/9, Wellington.

8 CLEM, A. (1995) "Commodity price volatility: Trends during 1975-84". Bureau of Labour Statistics Monthly Labour Review: USA.

9 COLLIER, P, \& GUNNING, J.W. (1996) "Policy towards commodity shocks in developing countries", IMF Working Paper, No. 96/84.

10 COOPER, RICHARD N. (1991) Economic Stabilization in Developing Countries, ICS Press: San Francisco, California.
11 CUDDINGTON, J. \& UZUA (1989) “Trends and cycles in the net batter terms of trade: A new approach", Economic Journal, 99: 426-442.

12 CUDDINGTON, J.T. \& LIANG, H. (1998) Commodity Price Volatility across Exchange Rate Regimes, Department of Economics: George Town University.

13 CUDDINGTON, J. (1994) "Long-run trends in 26 primary commodity prices: A disaggregated look at the Prebisch-Singer hypotheses", Journal of Development Economics, 39: 207-227.

14 DEATON, A.S. \& LAORWUE, G. (1992) "On the behaviour of commodity prices", the Review of Economic Studies, 59: 1-42.

15 DEHN, J. (2004) "Commodity price uncertainty in developing countries", Centre for the Study of African Economies Working Paper, WPS/2000-10.

16 ENDERS, W. (1995) Applied Econometric Time Series, John Wiley: London.

17 ENGLE, R.F. \& BOLLERSLEV, T. (1986) "Modelling the persistence of conditional variances", Econometric Reviews, 5: 1-50.

18 ENGLE, R. (1982) "Autoregressive conditional heteroskedascity with estimates of variance of United Kingdom inflation”, Econometrica, 50: 9871007.

19 FAO (2004) The State of Agricultural Commodity Markets, Food and Agricultural Organisation: Rome.

20 OCRAN, M.K. \& BIEKPE, N. (2005) "Commodity exports in SSA and economic growth: Evidence from panel data analysis", African Centre for Investment Analysis (ACIA) Working Paper, University of Stellenbosch.

21 OFFCUT, S.E. \& BLANDFORD, D. (1986) "Commodity market instability: Empirical techniques for analysis", Resource Policy, 12(1): 62-67.

22 GOURIEROUX, C. (1997) ARCH Models and Financial Applications, Springer Verlag: New York.

23 GRILLI, R.E.\& YANG, M.C. (1988) “Commodity prices, manufactured goods prices and the terms of trade of developing countries", World Bank Economic Review, 2: 1-48.

24 HAMILTON, J.D. (1994) Time Series Analysis, Princeton University Press: New Jersey.

25 HEIFNER, R. \& KINITHITA, R. (1994) "Differences among commodities in real price variability and drift", The Journal of Agricultural Economics Research, 45, 3: 10-20.

26 HARDING, D. \& PAGAN, A. (2002) "Dissecting the cycle: A methodological investigation", Journal of Monetary Economics, 49: 365-381. 
27 LEON, J \& SOTO, R. (1995) “Structural breaks and long-run trends in commodity prices", The World Bank Policy Research Working Paper, WPS 1406.

28 MARINKOV, M \& BURGER, P. (2005) “The various dimensions of commodity dependence in Africa”, South African Journal of Economics, 73: 2.

29 REINHART, C.M. \& WICKHAM, P. (1994) "Commodity prices: Cyclical weakness or secular decline?", IMF Papers, 41 (2): 175-213.

30 SWARAY, R.B. (2002) "Volatility of primary commodity prices: Some evidence from agricultural exports in Sub-Saharan Africa",
University of York Discussion Paper in Economics, 2002/06.

31 TAYLOR, S.J. (1987) Modelling Financial Time Series, John Wiley: New York.

32 UNCTAD (2003) Economic Development in Africa - Trade Performance and Commodity Dependence: United Nations: New York and Geneva.

33 WATSON, M. (1994) "Business cycle durations and post war stabilization of the US Economy," American Economic Review, 84: 24-46.

34 ZAKONIAN, J.M. (1994) "Threshold heteroskedasticity model”, Journal of Economic Dynamics and Control, 18: 931-955. 